\title{
Modulating Role for Thromboxane in the Tubuloglomerular Feedback Response in the Rat
}

\author{
William J. Welch and Christopher S. Wilcox \\ Division of Nephrology, Hypertension and Transplantation, Departments of Medicine, Pharmacology and Therapeutics, University of \\ Florida College of Medicine, Gainesville, Florida 32610; and Veterans Administration Medical Center, Gainesville, Florida 32602
}

\begin{abstract}
Söme studies have indicated that PGs can modulate the single nephron tubuloglomerular feedback (TGF) response. The aim of this study was to define the specific role of the vasoconstrictor PG, TX, by administration to rats of either vehicle (group $1 ; n=20$ ) or drugs that inhibit either cyclooxygenase (indomethacin [indo], $5 \mathrm{mg} \cdot \mathrm{kg}^{-1}$, group $2, n=17$ ), TX synthetase (UK-38,485 [UK], $100 \mathrm{mg} \cdot \mathrm{kg}^{-1}$, group 3, $n=19$ ), or TX receptors (SQ-29,548 [SQ], $8 \mathrm{mg} \cdot \mathbf{k g}^{-1}$, group 4, $n=14$, or $\mathrm{L}-641,953$ [L], $50 \mathrm{mg} \cdot \mathrm{kg}^{-1}$, group $5, n=8$ ). Indo reduced excretion of the prostacyclin derivative 6-keto-PGF $1 \alpha$ and $\mathbf{T X B}_{2}$ and lowered whole kidney GFR and renal plasma flow, whereas UK lowered excretion of $\mathrm{TXB}_{2}$ only and did not change basal renal hemodynamics. The TGF response (assessed from reduction in proximal tubule stop-flow pressure $\left(P_{\mathrm{sf}}, \mathrm{mmHg}\right.$ ) during increases in perfusion of the loop of Henle (LH) from 0 to $40 \mathrm{nl} \cdot \mathrm{min}^{-1}$ ) was unchanged after vehicle $(9.8 \pm 0.5-10.9 \pm 1.0, N S)$ but blunted $(P<0.001)$ by $40-65 \%$ in rats of groups $2-5$ (indo, 11.1 $\pm 1.0-4.4 \pm 0.7$; UK, 9.0 $\pm 0.8-$ 4.8 $\pm 0.7 ; \mathrm{SQ}, 10.3 \pm 0.6-4.8 \pm 0.6 ; \mathrm{L}, 10.7 \pm 0.5-6.7 \pm 1.3)$. This blunting was due to lower values for $P_{\text {sf }}$ at zeto $\mathrm{LH}$ flow after indo, SQ, and $L$, and higher values of $P_{\mathrm{sf}}$ at $40 \mathrm{nl} \cdot \min ^{-1} \mathrm{LH}$ flow after indo and UK. The fall in single nephron GFR (SNGFR, nl $\cdot \mathrm{min}^{-1}$ ) with increasing $\mathrm{LH}$ perfusion was unchanged after vehicle $(10.9 \pm 2.8-11.2 \pm 0.8)$ but was blunted $(P$ $<0.05)$ by $45-55 \%$ in rats given indo $(13.9 \pm 1.2-6.2 \pm 2.2)$ or UK (12.8 $\pm 2.1-7.0 \pm 1.5)$. UK produced dose-dependent reductions in $\mathrm{TXB}_{2}$ excretion $\left(\mathrm{IC}_{50}, 15 \mathrm{mg} \cdot \mathrm{kg}^{-1}\right)$ and inhibition of the TGF response $\left(\mathrm{IC}_{\mathbf{5 0}}: 30 \mathrm{mg} \cdot \mathrm{kg}^{-1}\right)$. After blockade of $\mathrm{TX}$ receptors by $S Q$, UK had no further affect on the TGF response. The fall in $P_{\text {of }}$ at high $\mathrm{LH}$ flow was blunted $(P<0.05)$ by indo and $U K$, whereas the rise in $P_{\text {sf }}$ at zero $L H$ flow was blunted by indo, SQ, and $L$. In conclusion, endogenous TX generation can modulate the reductions in $\mathbf{P}_{\text {sf }}$ and SNGFR during increased delivery of $\mathrm{NaCl}$ to the $\mathrm{LH}$.
\end{abstract}

\section{Introduction}

The tubuloglomerular feedback (TGF) ${ }^{1}$ response is an important intrarenal process regulating GFR. The response is initiated by an increased delivery of sodium and chloride to the

Address reprint requests to Dr. Wilcox, Division of Nephrology and Hypertension, Veterans Administration Medical Center, Gainesville, FL 32602.

Received for publication 7 May 1987 and in revised form 10 December 1987.

1. Abbreviations used in this paper: ANOVA, analysis of variance; AII, angiotensin II; GCMS, gas chromatography/mass spectroscopy; indo,

J. Clin. Invest.

(c) The American Society for Clinical Investigation, Inc.

$0021-9738 / 88 / 06 / 1843 / 07 \$ 2.00$

Volume 81, June 1988, 1843-1849 macula densa segment (1). The resulting changes in GFR are due to changes in plasma flow rate and glomerular capillary hydrostatic pressure, and perhaps also to changes in the glomerular capillary filtration coefficient (2). The mediators of these hemodynamic adjustments are not fully understood. Thus, the TGF response is blunted, but not abolished, by the blockade of either angiotensin-converting enzyme with captopril or angiotensin II (AII) receptors with saralasin (3). Likewise, the response is blunted, but not abolished, by blockade of cyclooxygenase with indomethacin (indo) or meclofenamate (4-6). Simultaneous blockade of AII generation and PG production with captopril and meclofenamate abolishes TGF-induced changes in glomerular capillary hydrostatic pressure although some changes in single nephron GFR (SNGFR) persist (7). The cyclooxygenase metabolite(s) that modulate the TGF response have not been elucidated.

TX is a cyclooxygenase metabolite that is produced by normal kidneys (8) or isolated glomeruli $(9-11)$ and might be a vasoconstrictor agent regulating GFR. Indeed, activation of TGF in a whole-kidney model in which vasoconstriction was induced by intrarenal infusion of hypettonic chloride-containing solutions was accompanied by release of thromboxane $B_{2}\left(T_{X B_{2}}\right)(8)$. The aim of the present study was to investigate the role of TX in a single-nephron model of the TGF response. We measured changes in SNGFR and proximal tubule stopflow pressure $\left(\mathrm{P}_{\mathrm{sf}}\right)$, which is an index of glomerular capillary hydrostatic pressure, during changes in the rate of perfusion of the loop of Henle (LH). The role of TX was investigated by administration of drugs inhibiting cyclooxygenase (indo), TX synthetase (UK-38,485 [UK]), or TX receptors (SQ-29,548 [SQ] and L-641,953 [L]). These drugs were selected because previous studies with inhibitors of cyclooxygenase had not discriminated between the roles of the vasoconstrictor PG, $\mathrm{TXA}_{2}$, and vasodilator PGs such as prostacyclin $\left(\mathrm{PGI}_{2}\right)$ or $\mathrm{PGE}_{2}$. The drugs used in the present studies inhibit the formation or action of TX at three distinct points. The specificity of action of these drugs was assessed first by measurements of the excretion of $\mathrm{PGs}$ or $\mathrm{TXB}_{2}$; second, by comparison of the dose-response relationship for UK on $\mathrm{TXB}_{2}$ excretion and TGF response; and third, by determining whether UK (a TX synthesis inhibitor) had any residual action on TGF after TX receptors were blocked by SQ.

\section{Methods}

Preparation and protocol. Experiments were performed on male Sprague-Dawley rats maintained on a rat chow diet (rodent laboratory chow 5001; Ralston-Purina Co., St. Louis, MO). Animals were anes-

indomethacin; 6 $\mathrm{kPGF}_{1 \alpha}$, 6-keto-PGF 1a ; L, L-641,953; LH, loop of Henle; MBP, mean blood pressure; PAH, para-aminohippuric acid; $\mathrm{PGI}_{2}$, prostacyclin; $\mathrm{P}_{\mathrm{sf}}$, proximal tubule stop-flow pressure; $R P F$, renal plasma flow; SQ, SQ-29,548; TGF, tubuloglomerular feedback; $\mathrm{UCV}_{\mathrm{Cl}} \mathrm{V}$, renal chloride excretion; $U K, U K-38,485 ; U_{K} V$, renal potassium excretion. 
thetized by intraperitoneal injection of inactin $\left(100 \mathrm{mg} \cdot \mathrm{kg}^{-1} ; \mathrm{BYK}\right.$, Gulden Konstanz, FRG) and prepared for micropuncture. Both external jugular veins were cannulated (PE-50), one for continuous infusion of inulin and para-aminohippuric acid (PAH), the other for administration of solutions. After tracheostomy, the right femoral artery was cannulated (PE-50) for blood sampling and pressure monitoring. Arterial blood pressure (BP) and heart rate were measured with a pressure transducer (Statham model P-23; Gould, Inc., Oxnard, CA) and recorded on a polygraph (model 5; Grass Instruments Co., Quincy, MA). The bladder was catheterized for urine collection from the right kidney. The left kidney was exposed by a lateral flank incision. Its ureter was cannulated (PE-10) and the kidney was mounted and stabilized in a plastic cup. The kidney was superfused with $0.15 \mathrm{M} \mathrm{NaCl}$ maintained at $37^{\circ} \mathrm{C}$ and illuminated via a quartz rod light. The animal was kept on a heated plexiglass surgical table and its body temperature was maintained by a servo heating device (model 73A; YSI, Yellow Springs, $\mathrm{OH})$ at $37^{\circ} \mathrm{C}$.

Inulin $\left(2 \mathrm{~g} \cdot \mathrm{dl}^{-1}\right)$, PAH $\left(0.2 \mathrm{~g} \cdot \mathrm{dl}^{-1}\right.$, Merck, Sharp and Dohme, West Point, PA), and albumin ( $3 \mathrm{~g} \cdot \mathrm{dl}^{-1}$, Sigma Chemical Co., St. Louis, MO) were dissolved in $0.15 \mathrm{M} \mathrm{NaCl}$ and the solution infused at $0.5 \mathrm{ml} \cdot 100 \mathrm{~g}$ body wt $(\mathrm{bw})^{-1} \cdot \mathrm{h}^{-1}$, after a priming dose of $0.5 \mathrm{ml}$ to maintain a euvolemic state. Experiments followed a standard protocol. After surgery, there was a 30-min equilibration period followed by a control period of $90 \mathrm{~min}$ (period 1) during which clearance and micropuncture measurements were made. Thereafter, test solutions or vehicle were infused over a 5-min period, followed by a $15-\mathrm{min}$ period for equilibration. There were six experimental groups. Group 1 received vehicle, group 2 received indo $\left(5 \mathrm{mg} \cdot \mathrm{kg}^{-1}\right)$, group 3 received UK $\left(100 \mathrm{mg} \cdot \mathrm{kg}^{-1}\right)$, group 4 received SQ $\left(8 \mathrm{mg} \cdot \mathrm{kg}^{-1}\right)$, and group 5 received $\mathrm{L}\left(50 \mathrm{mg} \cdot \mathrm{kg}^{-1}\right) .20 \mathrm{~min}$ after administration of vehicle or drugs, there was a 90-min experimental period (period 2) during which similar measurements and collections were made as in period 1 . Urine was collected during periods 1 and 2 , and a $0.6-\mathrm{ml}$ blood sample was drawn at the end of each. The different treatment groups are summarized in Table I. The preliminary results showed that the effects of SQ (group 4) and L on the TGF response were similar, and therefore a complete analysis of the response to TX receptor blockade was undertaken in the former group only.

Group 6 rats received SQ $\left(8 \mathrm{mg} \cdot \mathrm{kg}^{-1}\right)$ during period $2.15 \mathrm{~min}$ thereafter, clearance and micropuncture measurements were made, after which a second dose of SQ $\left(8 \mathrm{mg} \cdot \mathrm{kg}^{-1}\right)$ was given with UK (100 $\left.\mathrm{mg} \cdot \mathrm{kg}^{-1}\right)$. After another $15 \mathrm{~min}$, clearance and micropuncture measurements were repeated. Thus, in this group the effects of the blockade of TX synthesis with UK could be studied in animals whose TX receptors had been blocked by $\mathrm{SQ}$.

The dose-response relationships for the effect of UK on excretion of $\mathrm{TXB}_{2}$ and on the TGF response were studied in rats receiving the following doses $\left(\mathrm{mg} \cdot \mathrm{kg}^{-1}\right.$ ) of UK: $1,10,50,100$, and 500 . Clearance and micropuncture studies were performed as described above. One rat given the highest dose showed signs of toxicity (reduced BP) and its data were discarded.

Drugs. Indo inhibits cyclooxygenase and reduces the production of all PGs including $\mathrm{PGI}_{2}$ and TX $(4,6,7)$. Indo $\left(2.5 \mathrm{mg} \cdot \mathrm{ml}^{-1}\right.$, Sigma Chemical Co.) was dissolved in $1 \mathrm{M} \mathrm{Na}_{2} \mathrm{CO}_{3}$ solution and given to group 2 rats to assess the effects of nonselective inhibition of production of both vasodilator and vasoconstrictor PGs on the TGF response. UK (Pfizer-Central Research, Groton, CT) is a selective inhibitor of TX synthesis $(12-14,15)$ with the formula: 3-(1H-imidazol-1-ylmethyl)-2-methyl-1 H-indole-1-propanoic acid. It was dissolved in $1 \mathrm{~N}$ $\mathrm{NaOH}$ at $\mathrm{pH} 12.5$ and titrated with $1 \mathrm{~N} \mathrm{HCl}$ to $\mathrm{pH} 8.5$ to a concentration of $100 \mathrm{mg} \cdot \mathrm{ml}^{-1}$. It was given to group 3 rats to assess the effects of inhibition of TX synthesis on the TGF response. However, inhibition of TX synthesis in vitro in mononuclear cells can shunt endoperoxide metabolites of arachidonate towards synthesis of vasodilator PGs (16). Therefore, we also studied the action of two TX receptor antagonists to assess the role of TX receptor activation on the TGF response. SQ (Squibb Institute for Medical Research, Princeton, NJ) is a specific antagonist of $\mathrm{TXA}_{2}$ and stable endoperoxide analogues with a rela- tively short duration of action (17). It is a chemical analogue of TXA with the formula: $[1 S-[1 \alpha, 2 \beta(5 Z), 3 \beta, 4 \alpha]]-7-[3-[[2-[($ phenylamino) carboxyl] hydrazino] methyl]-7-oxabicyclo [2.2.1] hept-2-Y1]-5-heptenoic acid. It was given to group 4 rats. L (Merk-Frosst-Canada Inc., Pointe-Claire Dorval, Quebec, Canada) is a specific antagonist of $\mathrm{TXA}_{2}$ but has a longer duration of action (18) and is chemically distinct from $\mathrm{TXA}_{2}$. It has the formula: $\mathbf{R - 8 - f l u o r o - d i b e n z o}[\mathrm{b}, \mathrm{f}]$ thiepin3-carboxylic acid-5-oxide. It was given to group 5 rats to assess the effects of a chemically dissimilar TX receptor antagonist on the TGF response.

Chemical methods. Inulin was measured by an anthrone method and GFR was calculated from its clearance. PAH was measured by the Bratten-Marshall reaction; and renal plasma flow (RPF) was calculated from its clearance (19). Urine sodium $\left(\mathrm{Na}^{+}\right)$and potassium $\left(\mathrm{K}^{+}\right)$ concentrations were measured with a flame photometer (model 443; Instrumentation Laboratory, Inc., Lexington, MA). Urine chloride $\left(\mathrm{Cl}^{-}\right)$concentration was measured on a chloride meter (model 920M; Corning Medical, Medfield, MA).

\section{Assay for $T X B_{2}$ and 6-keto-PGF $F_{1 \alpha}\left(6 k P G F_{1 \alpha}\right)$}

The purification and assay of the $\mathrm{PGI}_{2}$ derivative $6 \mathrm{kPGF}_{1 \alpha}$ (Seragen Inc., Boston, $\mathrm{MA}$ ) and $\mathrm{TXB}_{2}$ in urine was developed from a previous method (8). Samples $(0.5 \mathrm{ml})$ of urine were spiked with $\sim 1,000 \mathrm{cpm}$ of $\left[{ }^{3} \mathrm{H}\right] \mathrm{TXB}_{2}$ (New England Nuclear, Boston MA) as a tracer to assess the individual recovery of each sample assayed and diluted with $0.5 \mathrm{ml}$ of deionized water to facilitate organic extraction. The $\mathrm{pH}$ was adjusted from 3.0 to 3.5 with $1.0 \mathrm{~N} \mathrm{HCl}$ and samples were extracted with 8-ml ethyl acetate. The organic phase was dried under nitrogen and dissolved in $50 \mu \mathrm{l}$ of acetone. Each $50-\mu \mathrm{l}$ sample was placed as a single spot on a $20 \times 20$-cm silica gel C-plate (Fisher Scientific Co., Pittsburgh, PA) at nine spots per plate. Standard $\mathrm{TXB}_{2}$ and $6 \mathrm{kPGF}_{1 \alpha}$ were spotted individually on one plate. Plates were developed in $\mathrm{CHCl}_{3} /$ MEOH/HOAC (90:10:5). The standards were visualized with anisealdehyde reagent spray; $\mathrm{TXB}_{2}$ appeared at reference point 0.65 and $6 \mathrm{kPGF}_{1 \alpha}$ at reference point 0.70 . Corresponding sample areas were scraped, extracted with $8 \mathrm{ml}$ of methyl formate, centrifuged at 2,600 $\mathrm{rpm}$, dried under nitrogen, and dissolved in $500 \mu \mathrm{l}$ of phosphate buffer (pH 7.4). A 50- $\mu$ l aliquot was used for calculation of individual sample recoveries, and the remainder was used for radioimmunoassay.

Radioimmunoassay was carried out in a $4^{\circ} \mathrm{C}$ ice bath in 12 $\times 75-\mathrm{cm}$ disposable glass tubes to which were added $200 \mu \mathrm{l}$ of phosphate buffer ( $\mathrm{pH} 7.4$ ) and $100 \mu \mathrm{l}$ of either standard or sample. Antisera (100 $\mu \mathrm{l}$, Seragen, Inc.) was added and the samples vortexed. After 15 min, $100 \mu \mathrm{l}$ of $\sim 100 \mathrm{cpm} \cdot \mu \mathrm{l}^{-1}$ of $\left[{ }^{3} \mathrm{H}\right]$ antigen (New England $\mathrm{Nu}-$ clear) was added to each tube and vortexed. The tubes were covered with parafilm and incubated at $4^{\circ} \mathrm{C}$ for $18 \mathrm{~h}$. Samples were precipitated with $500 \mu \mathrm{l}$ dextran-coated charcoal for $15 \mathrm{~min}$ and centrifuged at $2,650 \mathrm{rpm}$ for $10 \mathrm{~min}$. We recovered $500 \mu \mathrm{l}$ of each sample immediately and placed it in a scintillation vial for counting in a liquid scintillation counter (model LS7000; Beckman Instruments, Inc., Fullerton, $\mathrm{CA}$ ).

The assay had an interassay coefficient of variation $(n=31)$ for $\mathrm{TXB}_{2}$ of $7.6 \%$ and for $6 \mathrm{KPGF}_{1 \alpha}$ of $8.3 \%$. The sensitivity was 5-10 $\mathrm{pg} \cdot \mathrm{ml}^{-1}$. The accuracy was assessed each week by addition of $1,000 \mathrm{pg}$ of $\mathrm{TXB}_{2}$ and $6 \mathrm{kPGF}_{1 \alpha}$ to $1 \mathrm{ml}$ of rat urine. The results were $+975 \pm 22$ $\mathrm{pg} \cdot \mathrm{ml}^{-1}(n=23)$ for $6 \mathrm{KPGF}_{1 \alpha}$ and $+1,001 \pm 26 \mathrm{pg} \cdot \mathrm{ml}^{-1}(n=26)$ for $\mathrm{TXB}_{2}$. Dr. Garret A. Fitzgerald (Dept. of Clinical Pharmacology, Vanderbilt University Medical School, Nashville, TN) assayed three samples of urine from a rat given a large dose of indo using gas chromatography/mass spectroscopy (GCMS) methods. The results obtained ( $\mathrm{pg} \cdot \mathrm{ml}^{-1}$ ) in our radioimmunoassay, compared with the GCMS, were as follows: 1,292 vs. 430,292 vs. 90 , and 36 vs. 7. Therefore, our method overestimated $\mathrm{TXB}_{2}$ by three- to fivefold, perhaps because it also assayed the di- and tetra-nor derivatives of $\mathrm{TXB}_{2}$ (Fitzgerald, $\mathrm{G}$., personal communication), but provided a close correlation with the pattern of changes in $\mathrm{TXB}_{2}$ excretion, as assessed by GCMS.

Micropuncture preparation. The kidney was viewed with a stereomicroscope (model 5A Wild/Heerbrugg; E. Leitz Co., Rockleigh, NJ). 
For microperfusion, a pipette (3-5 $\mu \mathrm{m}$ o.d.) containing $0.15 \mathrm{M}$ saline stained with fast green number 5 (Sigma Chemical Co.) was inserted into a proximal tubule. After a 5-10-nl injection, several proximal loops of the same nephron were identified. A microperfusion pipette (4-6 $\mu \mathrm{m}$ o.d.) containing artificial tubular fluid and driven by a nanoliter perfusion pump (model A1400; World Precision Instruments, New Haven, CT) was inserted into the end proximal superficial loop to perfuse the LH. Artificial tubular fluid solution contained $132 \mathrm{mM}$ $\mathrm{NaCl}, 4 \mathrm{mM} \mathrm{NaHCO}, 5 \mathrm{mM} \mathrm{KCl}, 2 \mathrm{mM} \mathrm{CaCl}_{2}, 7 \mathrm{mM}$ urea, and 2 $\mathrm{mM} \mathrm{MgCl}$. The nanoliter perfusion pump was calibrated in vitro with isotopic techniques and in vivo volumetrically. An immobile wax block was inserted into the nephron proximal to the site of perfusion by a pipette (6-8 $\mu \mathrm{m}$ o.d.) containing bone wax stained with sudan black and connected to a hydraulic microdrive unit (model 5; Trent Wells, Inc., South Gate, CA). A pressure-measuring pipette (1-2 $\mu \mathrm{m}$ o.d.) was inserted into the nephron proximal to the wax block to measure $P_{s f}$. This pipette was filled with $2 \mathrm{M} \mathrm{NaCl}$ and connected to a servo-null micropressure device (model 4A; Instrumentation for Physiology and Medicine, La Jolla, CA). The pressure system was calibrated during each experiment. $P_{s f}$ was recorded at each perfusion interval when it had reached a stable value after 1 to $3 \mathrm{~min}$. The loop was perfused at $0,10,20,30$, and $40 \mathrm{nl} \cdot \mathrm{min}^{-1}$ in random order.

In separate animals of groups 1-3, SNGFR was measured in addition to $\mathrm{P}_{\mathrm{sf}}$ in response to perfusion of the $\mathrm{LH}$ at zero and $40 \mathrm{nl} \cdot \mathrm{min}^{-1}$ after administration of vehicle, indo, or UK. After completion of $\mathbf{P}_{\mathbf{s f}}$ measurements, the tubule was vented and a collection pipette (8-12 $\mu \mathrm{m}$ o.d.) filled with mineral oil stained with sudan black was inserted upstream. A timed fluid collection was made during perfusion of the $\mathrm{LH}$ at 0 or $40 \mathrm{nl} \cdot \mathrm{min}^{-1}$. A column of oil three to four times the width of the tubule lumen was injected downstream from the pipette, and tubular fluid was aspirated with sufficient negative pressure to maintain the position of the oil column. A second collection of tubular fluid was made after changing the rate of LH perfusion to 0 or $40 \mathrm{nl} \cdot \mathrm{min}^{-1}$. This collection was taken from a more proximal site of the same nephron after venting of the first collection site. Tubular fluid volumes were measured in a constant-bore glass capillary by a filar micrometer. Rats used for SNGFR measurements received an infusion of $\left[{ }^{3} \mathrm{H}\right]$ inulin $\left(50 \mu \mathrm{Ci} \cdot 100 \mathrm{~g} \mathrm{bw}^{-1} \cdot \mathrm{h}^{-1}\right)$ and $\left[{ }^{14} \mathrm{C}\right] \mathrm{PAH}(0.4 \mu \mathrm{Ci} \cdot 100 \mathrm{~g}$ $\left.\mathrm{bw}^{-1} \cdot \mathrm{h}^{-1}\right)$ delivered in similar volumes as the animals receiving unlabeled inulin and PAH. Aliquots of tubular fluid, urine, and plasma were counted in a liquid scintillation counter (model LS7800; Beckman Instruments, Inc.).

$P_{s f}$ was measured at zero loop perfusion at the beginning and end of each series. If these values differed by $>1 \mathrm{mmHg}$, the data were discarded. It was technically harder to undertake recovery measurements of SNGFR. In 32 preliminary studies, SNGFR was measured first at zero loop perfusion; the SNGFRs recorded in this group at 0 and 40 $\mathrm{nl} \cdot \mathrm{min}^{-1}$ of LH perfusion were $35 \pm 2$ and $21 \pm 2 \mathrm{nl} \cdot \mathrm{min}^{-1}$, respectively. In 13 rats, SNGFR was measured first at $40 \mathrm{nl} \cdot \mathrm{min}^{-1}$ loop perfusion; the SNGFRs recorded in this group at 0 and $40 \mathrm{nl} \cdot \mathrm{min}^{-1}$ of $\mathrm{LH}$ perfusion were similar at $37 \pm 2$ and $20 \pm 2 \mathrm{nl} \cdot \mathrm{min}^{-1}$. Therefore, the order in which measurements were made did not appear to influence the response. Nevertheless, the order of studies was randomized between rats.

Values are reported as mean \pm 1 SEM. Differences between groups were assessed by analysis of variance (ANOVA) with a Student's $t$ test to assess posthoc differences. Values were taken as statistically significant at $P<0.05$.

\section{Results}

The effect of each drug treatment on mean blood pressure (MBP) and whole kidney function is shown in Table I. The body weights were not different between the groups. The data obtained in the basal state (period 1) did not differ between groups. The results of an ANOVA indicated that, compared with vehicle, indo reduced urine flow, whereas UK increased urine flow and chloride excretion.

The effects of drugs on renal excretion of $\mathrm{TXB}_{2}$ and $6 \mathrm{kPGF}_{1 \alpha}$ are shown in Fig. 1. Urine volumes were insufficient for measuring $\mathrm{PG}$ or $\mathrm{TXB}_{2}$ excretion in $\sim 10 \%$ of the rats. During period 1 , there were no differences in excretion between the three groups. Administration of vehicle (group 1) did not change excretion of $\mathrm{TXB}_{2}$ or $6 \mathrm{kPGF}_{1 \alpha}$ (data not shown). Compared with vehicle, treatment with indo (group 2) or UK (group 3) decreased the excretion of $\mathrm{TXB}_{2}$ consistently, whereas the excretion of $6 \mathrm{kPGF}_{1 \alpha}$ was decreased only by indo.

Group mean changes in $\mathbf{P}_{\mathrm{sf}}$ during increases in the rate of

Table I. Body Weight, MBP, and Renal Function before (Period I) and after (Period II) Administration of Vehicle or Drug

\begin{tabular}{|c|c|c|c|c|c|c|c|c|c|c|c|c|}
\hline & & \multirow[b]{2}{*}{ Body weight } & \multicolumn{2}{|c|}{ MBP } & \multicolumn{3}{|c|}{ GFR } & \multicolumn{3}{|c|}{ RPF } & \multicolumn{2}{|c|}{ Filtration fraction } \\
\hline & & & 1 & 2 & 1 & & 2 & 1 & & 2 & 1 & 2 \\
\hline & & $g$ & \multicolumn{2}{|c|}{$m m H g$} & \multicolumn{3}{|c|}{$m l \cdot \min ^{-1}$} & \multicolumn{3}{|c|}{$m l \cdot \min ^{-1}$} & & \\
\hline \multicolumn{2}{|c|}{ Vehicle $(n=20)$} & $234 \pm 10$ & $116 \pm 2$ & $114 \pm 2$ & $1.82 \pm 0.11$ & \multicolumn{2}{|c|}{$1.68 \pm 0.09$} & \multicolumn{2}{|c|}{$5.38 \pm 0.34$} & $4.76 \pm 0.36$ & $0.35 \pm 0.02$ & $0.33 \pm 0.02$ \\
\hline indo $(n=$ & & $234 \pm 12$ & $115 \pm 3$ & $112 \pm 3$ & $2.02 \pm 0.16$ & \multicolumn{2}{|c|}{$1.66 \pm 0.11$} & \multicolumn{2}{|c|}{$6.22 \pm 0.61$} & $4.74 \pm 0.44$ & $0.34 \pm 0.02$ & $0.37 \pm 0.02$ \\
\hline \multicolumn{2}{|c|}{ UK $(n=19)$} & \multirow{2}{*}{$\begin{array}{l}239 \pm 12 \\
251 \pm 14\end{array}$} & \multirow{2}{*}{$\begin{array}{l}117 \pm 2 \\
115 \pm 2\end{array}$} & & $1.95 \pm 0.11$ & \multicolumn{2}{|c|}{$1.76 \pm 0.14$} & \multicolumn{2}{|c|}{$5.73 \pm 0.41$} & $4.93 \pm 0.48$ & $0.35 \pm 0.02$ & $0.38 \pm 0.02$ \\
\hline \multicolumn{2}{|c|}{$\mathrm{SQ}(n=14)$} & & & $\begin{array}{l}110 \pm 2 \\
111 \pm 3\end{array}$ & $1.97 \pm 0.21$ & \multicolumn{2}{|c|}{$1.69 \pm 0.15$} & \multicolumn{2}{|c|}{$6.21 \pm 0.56$} & $6.03 \pm 0.78$ & $0.32 \pm 0.03$ & $0.31 \pm 0.02$ \\
\hline & \multicolumn{2}{|r|}{ UV } & \multicolumn{4}{|c|}{$\mathrm{U}_{\mathrm{Ne}_{\mathrm{N}} \mathrm{V}}$} & \multicolumn{4}{|c|}{$\mathbf{U}_{\mathbf{k}} \mathbf{V}$} & \multicolumn{2}{|c|}{$\mathrm{UaV}_{\mathrm{a}}$} \\
\hline & 1 & 2 & & 1 & 2 & & & & & 2 & 1 & 2 \\
\hline & \multicolumn{2}{|r|}{$\mu l \cdot \min ^{-1}$} & \multicolumn{4}{|c|}{$\mathrm{\mu mol} \cdot \mathrm{min}^{-1}$} & \multicolumn{4}{|c|}{$\mu \mathrm{mol} \cdot \mathrm{min}^{-1}$} & $\mu \mathrm{mol}$. & $\operatorname{nin}^{-1}$ \\
\hline Vehicle & $8.0 \pm 0.6$ & $8.9 \pm 0.9$ & & $94 \pm 0.024$ & $0.191 \pm 0$. & & 1.821 & 0.291 & & $1 \pm 0.366$ & $1.30 \pm 0.23$ & $1.57 \pm 0.33$ \\
\hline indo & $8.6 \pm 1.0$ & $6.9 \pm 1.2^{*}$ & & $47 \pm 0.1085$ & $0.182 \pm 0$ & & 1.763 & 0.516 & & $0 \pm 0.278$ & $1.38 \pm 0.48$ & $1.17 \pm 0.48$ \\
\hline UK & $7.6 \pm 0.7$ & $10.5 \pm 1.2^{*}$ & & $12 \pm 0.036$ & $0.283 \pm 0$ & & 1.715 & 0.366 & & $3 \pm 0.363$ & $1.28 \pm 0.30$ & $2.30 \pm 0.31^{*}$ \\
\hline SQ & $7.4 \pm 1.2$ & $8.3 \pm 1.9$ & 0. & $94 \pm 0.033$ & $0.233 \pm 0$ & & 1.494 & 0.236 & & $9 \pm 0.235$ & $1.07 \pm 0.20$ & $0.90 \pm 0.24$ \\
\hline
\end{tabular}

Mean \pm SEM values. $n$, Number of rats studied. $U V$, urine flow; $U_{N a} V$, renal sodium excretion. Significance of differences compared with vehicle, using ANOVA and posthoc $t$ tests: $* P<0.05$. 


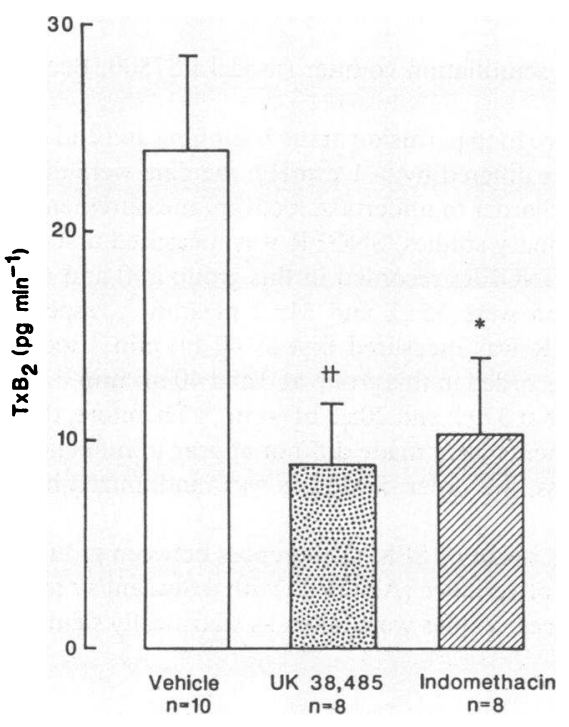

perfusion of the $\mathrm{LH}$ from 0 to $40 \mathrm{nl} \cdot \mathrm{min}^{-1}$ are shown in Fig. 2 . In the basal state during period 1, there were no differences between the groups. Administration of vehicle (group 1) did not change the response. In contrast, significant reductions in $\mathbf{P}_{\mathrm{sf}}$ responses were seen after administration of indo, UK, SQ, or $\mathrm{L}$. Compared with vehicle-treated group 1 rats, the $P_{s f}$ responses to increasing perfusion of the LH were blunted ( $P$ $<0.005$ ) in groups 2-5.

Table II contains more detailed data relating to the effect of drugs on the TGF response. This table shows group mean values for $P_{s f}$ and SNGFR recorded during perfusion of the $L H$ at 0 and $40 \mathrm{nl} \cdot \mathrm{min}^{-1}$. In the basal state (period 1) the values of $P_{\text {sf }}$ at 0 and $40 \mathrm{nl} \cdot \mathrm{min}^{-1}$ were not different among groups. However, the results of ANOVA and posthoc $t$ tests demonstrate that after treatment (period 2), the $\mathrm{P}_{\mathrm{sf}}$ at zero perfusion of the LH was lower in animals pretreated with indo ( $P$ $<0.005)$, SQ $(P<0.01)$, or $\mathrm{L}(P<0.05)$ compared with those receiving vehicle, whereas the $P_{s f}$ during perfusion of the $\mathrm{LH}$ at $40 \mathrm{nl} \cdot \mathrm{min}^{-1}$ was greater $(P<0.05)$ in animals that had received indo or UK. During period 1, there were no differences between the groups for the changes in $\mathrm{P}_{\mathrm{sf}}$ during increase in $\mathrm{LH}$ perfusion from 0 to $40 \mathrm{nl} \cdot \mathrm{min}^{-1}$. During period 2, administration of indo, UK, SQ, and $L$ all reduced $(P<0.005)$ the TGF response compared with group 1 rats that had received vehicle. During period 1, the values of SNGFR recorded at perfusion of the $\mathrm{LH}$ at 0 and $40 \mathrm{nl} \cdot \mathrm{min}^{-1}$ and the differences in SNGFR between these two perfusion rates did not differ between groups (Table II). After administration of vehicle (group 1), the SNGFR response to changes in $\mathrm{LH}$ perfusion were comparable. In contrast, after administration of indo (group 2) or UK (group 3) there were significant reductions in SNGFR responses to increasing LH perfusion. After indo, the overall blunting of the TGF response assessed from changes in $P_{s f}$ was comparable with that assessed from changes in SNGFR and averaged -60 and $-58 \%$, respectively. After UK, the blunting was also comparable, -47 and $-45 \%$, respectively. However, there was more variability in the SNGFR data, and no signifcant changes in SNGFR at 0 or $40 \mathrm{nl} \cdot \mathrm{min}^{-1}$ of $\mathrm{LH}$ perfusion were detected after either drug. Inspection of the data indicated that the order in which measurements of SNGFR were

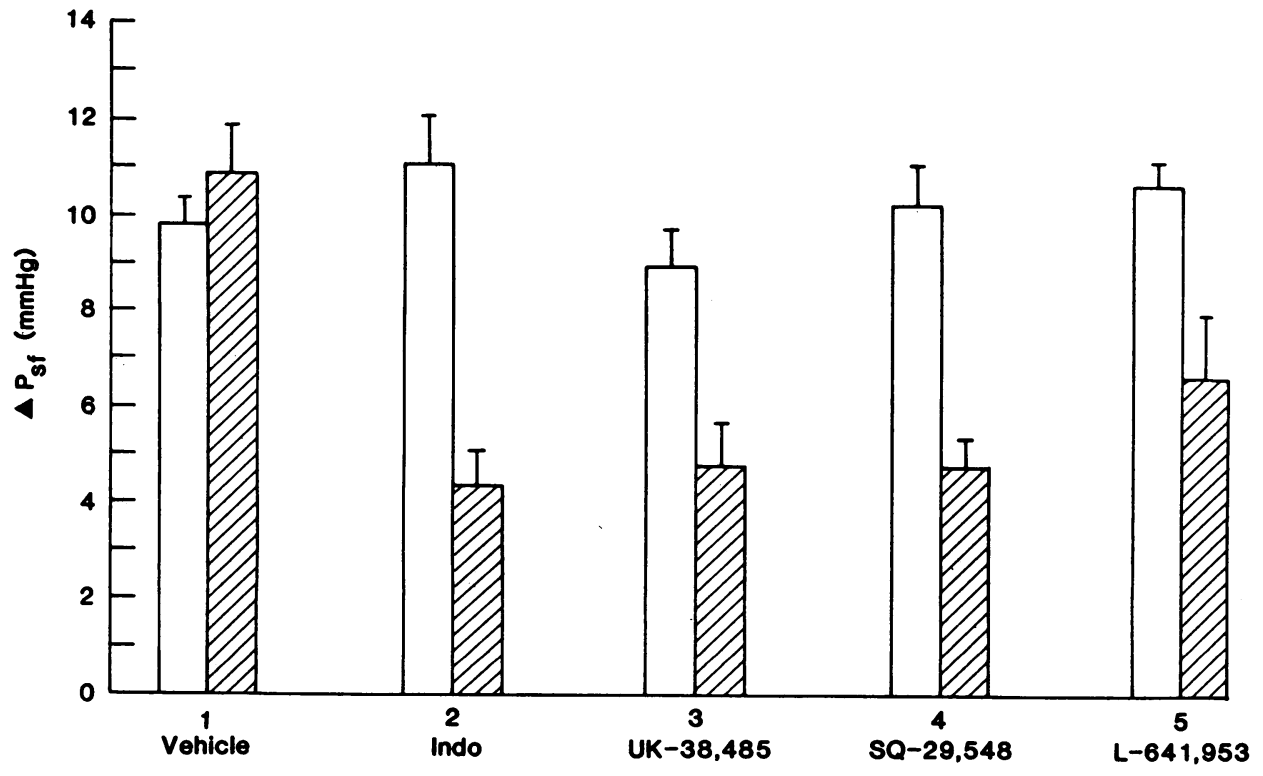

Figure 2. Mean ( \pm SEM) values are shown for changes in $\mathrm{P}_{\mathrm{sf}}$ during increases in $\mathrm{LH}$ perfusion from 0 to $40 \mathrm{nl} \cdot \mathrm{min}^{-1}$ during periods 1 and 2 in groups 1-5. Data were analyzed by ANOVA with posthoc $t$ test. During period 1, there were no differences between groups. However, during period 2, the values in groups 2-5 were all lower than those in group $1(P<0.005)$. 


\begin{tabular}{|c|c|c|c|c|c|c|}
\hline & \multicolumn{3}{|c|}{ Period I } & \multicolumn{3}{|c|}{ Period II } \\
\hline & \multicolumn{6}{|c|}{ LH perfusion rate $\left(n l \cdot \mathrm{min}^{-1}\right)$} \\
\hline & 0 & 40 & $\Delta(0$ to 40$)$ & 0 & 40 & $\Delta(0$ to 40$)$ \\
\hline \multicolumn{7}{|l|}{$\mathrm{P}_{\mathrm{sf}}(m m H g)$} \\
\hline Vehicle $(n=19)$ & $31.9 \pm 0.9$ & $22.8 \pm 0.9$ & $9.8 \pm 0.8$ & $32.7 \pm 1.1$ & $22.6 \pm 0.8$ & $10.0 \pm 0.7$ \\
\hline indo $(n=15)$ & $32.1 \pm 1.2$ & $21.0 \pm 1.1$ & $11.1 \pm 1.0$ & $28.8 \pm 1.3^{*}$ & $24.4 \pm 1.1^{*}$ & $4.4 \pm 0.7^{\S}$ \\
\hline UK $(n=19)$ & $32.5 \pm 1.4$ & $23.5 \pm 1.0$ & $9.0 \pm 0.8$ & $30.8 \pm 1.6$ & $26.0 \pm 1.1^{*}$ & $4.8 \pm 0.7^{\S}$ \\
\hline SQ $(n=14)$ & $31.8 \pm 0.9$ & $21.1 \pm 0.8$ & $10.3 \pm 0.6$ & $28.4 \pm 0.9^{\ddagger}$ & $23.6 \pm 0.6$ & $4.8 \pm 0.6^{\S}$ \\
\hline $\mathrm{L}(n=8)$ & $33.6 \pm 1.1$ & $22.5 \pm 1.1$ & $10.9 \pm 0.5$ & $30.6 \pm 1.7^{*}$ & $24.5 \pm 1.2$ & $6.1 \pm 0.7^{\S}$ \\
\hline \multicolumn{7}{|l|}{ SNGFR $\left(n l \cdot \mathrm{min}^{-1}\right)$} \\
\hline Vehicle $(n=7)$ & $27.0 \pm 4.3$ & $16.0 \pm 2.0$ & $10.9 \pm 2.8$ & $27.4 \pm 2.4$ & $16.1 \pm 2.3$ & $11.2 \pm 0.8$ \\
\hline indo $(n=6)$ & $36.0 \pm 3.9$ & $22.0 \pm 3.6$ & $13.9 \pm 1.2$ & $30.4 \pm 4.0$ & $24.2 \pm 4.3$ & $6.2 \pm 2.2^{*}$ \\
\hline UK $(n=17)$ & $28.9 \pm 2.7$ & $16.1 \pm 2.1$ & $12.8 \pm 2.1$ & $25.7 \pm 2.7$ & $18.6 \pm 2.1$ & $7.0 \pm 1.5^{*}$ \\
\hline
\end{tabular}

Mean \pm SEM values. $n$, Number of rats studied. Significance of changes compared with vehicle using ANOVA and posthoc $t$ tests: ${ }^{*} P<$ 0.05 . ${ }^{\ddagger} P<0.01$. ${ }^{\S} P<0.005$.

made did not affect the results obtained. Thus, after vehicle administration, eight rats were studied first at zero loop perfusion; their values for SNGFR at 0 and $40 \mathrm{nl} \cdot \mathrm{min}^{-1}$ of loop perfusion were $29 \pm 4$ and $19 \pm 3 \mathrm{nl} \cdot \mathrm{min}^{-1}$, compared with values of $30 \pm 4$ and $17 \pm 4 \mathrm{nl} \cdot \mathrm{min}^{-1}$ in five rats studied first at $40 \mathrm{nl} \cdot \mathrm{min}^{-1}$. After indo, nine rats were studied first at zero loop perfusion; their values for SNGFR at 0 and 40 were $27 \pm 3$ and $20 \pm 4$ compared with values of $24 \pm 5$ and $21 \pm 3$ in three rats studied first at $40 \mathrm{nl} \cdot \mathrm{min}^{-1}$. After UK, seven rats were studied first at zero loop perfusion; their values for SNGFR at 0 and $40 \mathrm{nl} \cdot \mathrm{min}^{-1}$ were $22 \pm 3$ and $16 \pm 2 \mathrm{nl} \cdot \mathrm{min}^{-1}$ compared with values of $25 \pm 1$ and $18 \pm 3$ in six rats studied first at 40 $\mathrm{nl} \cdot \mathrm{min}^{-1}$.

The dose-response relationship for UK on renal $\mathrm{TXB}_{2}$ excretion is compared with that on the TGF response in Fig. 3. The fractional changes in $\mathrm{TXB}_{2}$ excretion and TGF during period 2 (after administration of the drug) are compared with the control period $1 . \mathrm{TXB}_{2}$ excretion was maximally suppressed by $100 \mathrm{mg} \cdot \mathrm{kg}^{-1}$; the $\mathrm{IC}_{50}$ was $15 \mathrm{mg} \cdot \mathrm{kg}^{-1}$. The TGF response was maximally suppressed by $100 \mathrm{mg} \cdot \mathrm{kg}^{-1}$; the $\mathrm{IC}_{50}$ was $30 \mathrm{mg} \cdot \mathrm{kg}^{-1}$.

The mean values of $P_{s f}$ at incremental rates of $\mathrm{LH}$ perfusion are shown in Fig. 4. During period 1, there was a sigmoidal reduction in $\mathrm{P}_{\mathrm{sf}}$ with increasing $\mathrm{LH}$ perfusion in each group. The rate of $\mathrm{LH}$ perfusion associated with a $50 \%$ reduction in $\mathrm{P}_{\mathrm{sf}}$ averaged $15-20 \mathrm{nl} \cdot \mathrm{min}^{-1}$. After administration of vehicle, there were no consistent changes. Indo and SQ flattened the response by reducing $\mathrm{P}_{\mathrm{sf}}$ at low and high rates of $\mathrm{LH}$ perfusion, whereas the effects of UK were significant only at the high rates of $\mathrm{LH}$ perfusion.

The $\mathrm{P}_{\mathrm{sf}}$ at graded rates of $\mathrm{LH}$ perfusion was studied in seven rats before administration of drugs, after administration of SQ, and after UK plus SQ (Fig. 5). SQ reduced $P_{\text {sf }}$ at zero perfusion of the LH and increased it at $40 \mathrm{nl} \cdot \mathrm{min}^{-1}$ of $\mathrm{LH}$ perfusion, as in the previous series (Fig. 4). After administration of SQ, UK had no further effect on $\mathrm{P}_{\mathrm{sf}}$ at any rate of $\mathrm{LH}$ perfusion, although the value at zero $\mathrm{LH}$ perfusion was now not quite significantly lower than during period 1 .

\section{Discussion}

The main finding of our study was that drugs acting at three distinct sites in the pathway leading to $\mathrm{TXA}_{2}$ synthesis or ac- tion all suppressed changes in SNGFR and/or $P_{s f}$ during increased delivery of filtrate to the LH. Thus, TGF was blunted by $\sim 40-65 \%$ after inhibition of cyclooxygenase with indo, after inhibition of TX synthesis with UK, or after inhibition of TX receptors with SQ or $L$. The blunting of TGF-induced changes in glomerular capillary pressure by indo, SQ, and $\mathrm{L}$ were due to lower values at zero LH perfusion, whereas indo and $\mathrm{UK}$ increased the values at $40 \mathrm{nl} \cdot \mathrm{min}^{-1}$ of $\mathrm{LH}$ perfusion.

The conclusions of this study depend critically upon the specificity of the drugs used. Indo is a noncompetitive inhibitor of cyclooxygenase that inhibited the renal synthesis of $\mathrm{TXA}_{2}$ and $\mathrm{PGI}_{2}$ (as assessed from excretion of their metabo-

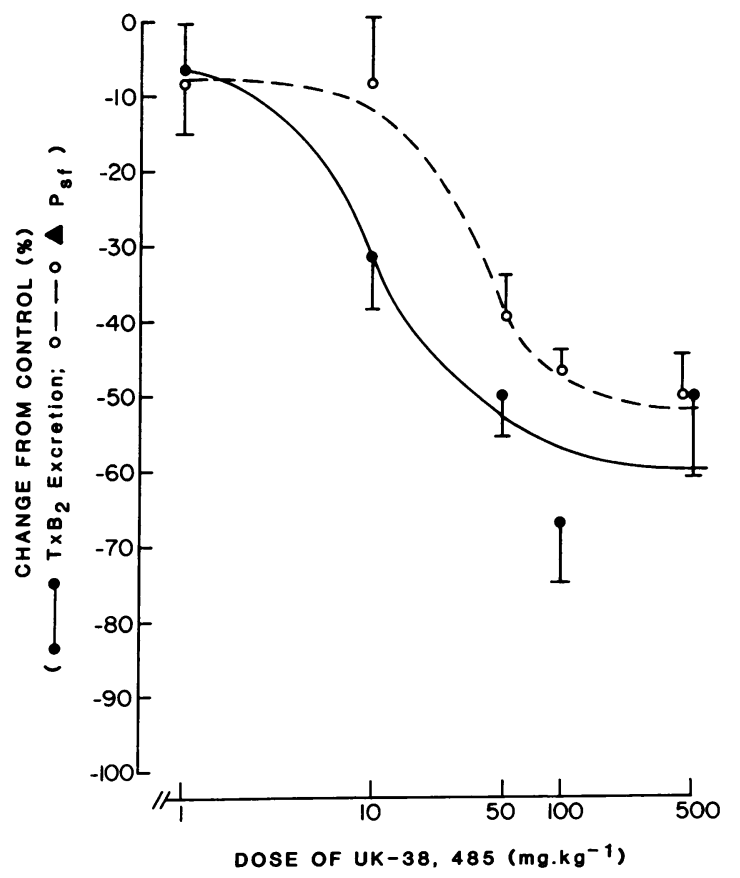

Figure 3. Mean $\pm \mathrm{SEM}$ values for the dose-response effects of $\mathrm{UK}$ on the excretion of $\mathrm{TXB}_{2}$ and the TGF response (from change in $\mathrm{P}_{\mathrm{sf}}$ during LH perfusion from 0 to $40 \mathrm{nl} \cdot \mathrm{min}^{-1}$ ). Data shown are for fractional changes in responses during period 2 compared with period 1 . 


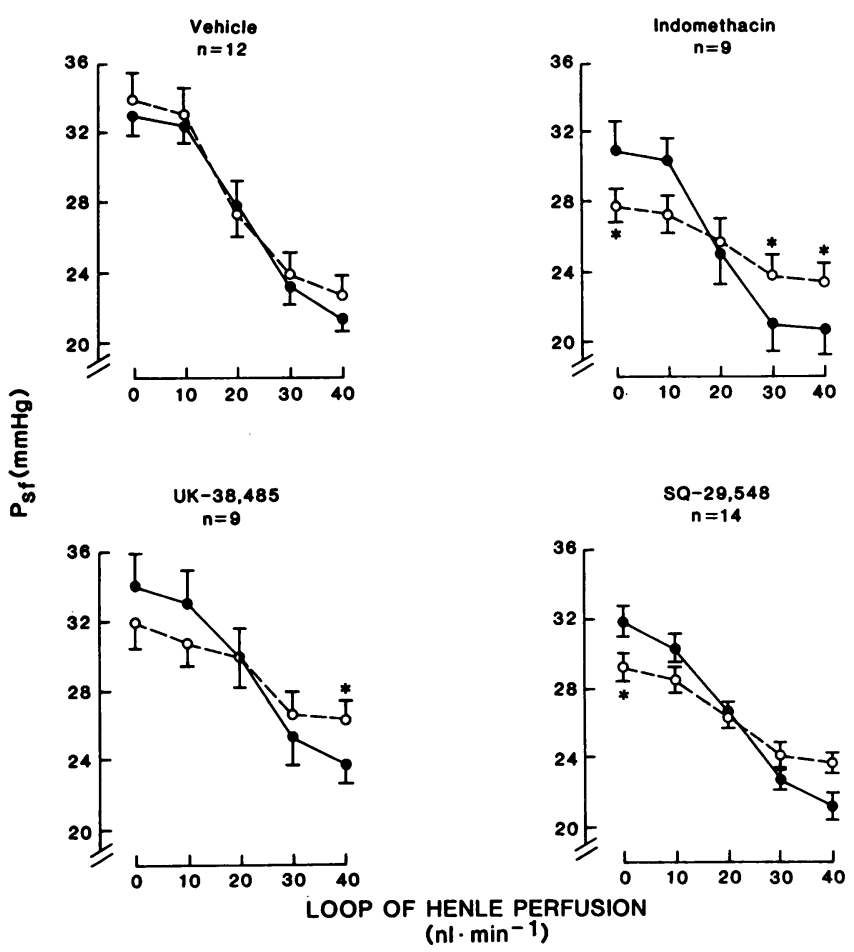

Figure 4. Mean ( \pm SEM) values for $P_{s f}$ at graded $L H$ perfusion for period $1(\bullet)$ and period $2(0)$ in groups 1-4. Compared with period 1: $* P<0.05$, using ANOVA and posthoc $t$ tests.

lites) over the time at which it blunted the TGF response. In contrast, UK is a competitive inhibitor of TX synthetase (15, 16). It produced dose-dependent inhibition of the TGF response and excretion of $\mathrm{TXB}_{2}$ without affecting $6 \mathrm{kPGF}_{1 \alpha}$. This confirms previous studies using GCMS (14), thin-layer chromatography (13), or radioimmunoassay (15) of samples of urine or superfusates from isolated glomeruli, which showed

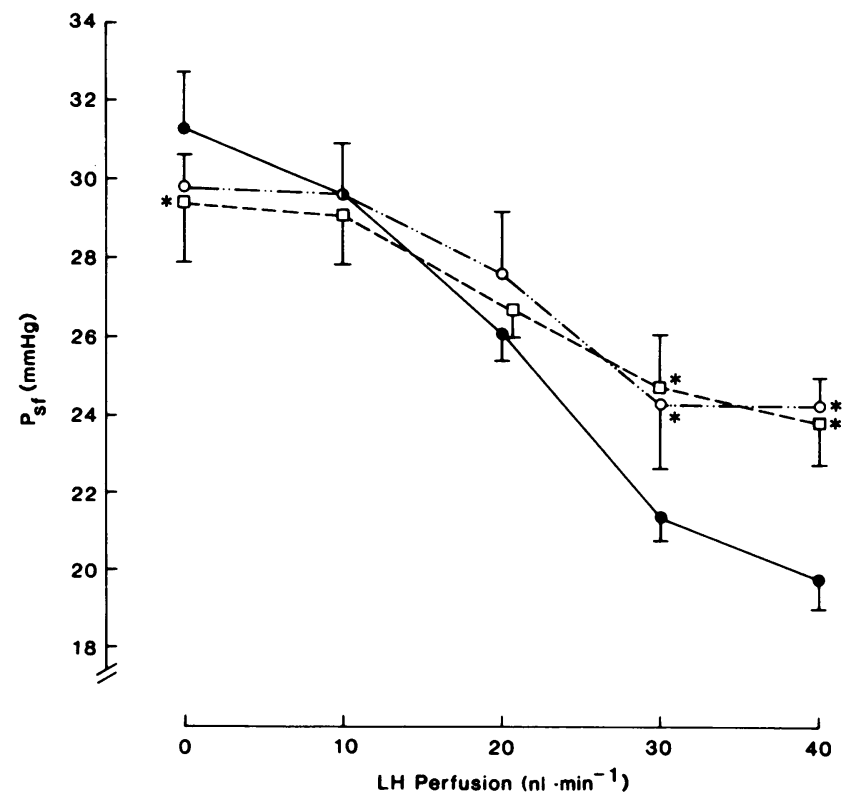

Figure 5. Mean \pm SEM values of $P_{s f}$ at graded $L H$ perfusion for period 1 (control [๑]), period 2 (SQ [ㅁ]), and period 3 (SQ and UK [o]) in rats of group 6. Compared with period $1: * P<0.05$. that UK is a specific inhibitor of renal TX synthesis without demonstrable effects on $\mathrm{PGI}_{2}$ or $\mathrm{PGE}_{2}$. However, maximal doses of UK reduced TGF responses and $\mathrm{TXB}_{2}$ excretion by only $50-60 \%$. The $\mathrm{IC}_{50}$ for $\mathrm{TXB}_{2}$ excretion $\left(15 \mathrm{mg} \cdot \mathrm{kg}^{-1}\right)$ was similar to that for TGF $\left(30 \mathrm{mg} \cdot \mathrm{kg}^{-1}\right)$, which implies that the action of UK in inhibiting TGF could indeed relate to inhibition of renal TXA 2 generation. UK might have blunted TGF by shunting PG endoperoxides towards synthesis of some unmeasured PGs. To test this hypothesis, rats were pretreated with a TX receptor antagonist, after which there was no additional effect of a full dose of UK. We therefore concluded that the blunting of TGF by UK was indeed best attributed to a blunting of $\mathrm{TXA}_{2}$ synthesis. The results also showed that two structurally quite dissimilar TX receptor antagonists produced a comparable degree of inhibition of TGF response to that produced by a TX synthetase antagonist. SQ is a relatively short-acting competitive antagonist of $\mathrm{TXA}_{2}$-induced arteriolar vasoconstriction or platelet aggregation; it is chemically related to TX (17). L is a highly specific antagonist of TX-and PG endoperoxide-mediated platelet aggregation, smooth muscle contraction, or vasoconstriction (18); it has a prolonged duration of action and is structurally distinct from TX.

TX is a vasoconstrictor, and therefore the effects of drugs blocking its synthesis or receptors should be apparent during the vasoconstrictor phase of the TGF response at high LH perfusion. Indeed, indo and $\mathrm{UK}$ blunted the fall in $\mathrm{P}_{\mathrm{sf}}$ during perfusion of the $\mathrm{LH}$ at $40 \mathrm{nl} \cdot \mathrm{min}^{-1}$, which is consistent with blunting of vasoconstriction. However, SQ and $\mathrm{L}$ did not have consistent effects at $40 \mathrm{nl} \cdot \mathrm{min}^{-1}$. Moreover, data were more variable for SNGFR, where no clear effects of indo or UK were seen at $40 \mathrm{nl} \cdot \mathrm{min}^{-1}$ of $\mathrm{LH}$ perfusion, although both drugs blunted the overall TGF-induced changes in SNGFR by 45-55\%. Indo, $S Q$, and $L$ reduced $P_{s f}$ significantly during perfusion of the $\mathrm{LH}$ at zero flow, implying that they blunted the vasodilator arm of the TGF response. Previously, indo has been shown to blunt the overall TGF response assessed from changes in early proximal flow rate without changing signifcantly the early proximal flow rate at zero $\mathrm{LH}$ perfusion (4). A blunting of the vasodilator and vasoconstrictor arms of the TGF-induced changes in $\mathbf{P}_{\mathrm{sf}}$ might relate to diminished production by indo of both vasodilator PGs and TXA $\mathrm{TH}_{2}$. However, it is hard to reconcile this conclusion with results of previous studies (4), which showed the time course of inhibition of the TGF response by indo did not correspond with that for inhibition of PG excretion. Moreover, this would not explain why administration of $\mathrm{SQ}$ and $\mathrm{L}$ also reduced $\mathrm{P}_{\mathrm{sf}}$ during perfusion of the $\mathrm{LH}$ at zero flow. The values for $\mathrm{P}_{\mathrm{sf}}$ and SNGFR at zero loop perfusion were rather lower than in some previous studies. TX receptor antagonists can be partial agonists at vascular sites (20), but SQ and $L$ do not have significant agonist activity on smooth muscle or rat aortic strips $(17,18)$. In recent preliminary studies, we have shown that $S Q$ and $L$ release renin and AII, which might have led to vasoconstriction and therefore to a lower $P_{s f}$ at zero $\mathrm{LH}$ flow (21).

The kidney releases $\mathrm{TXB}_{2}$ into renal lymph and urine (8). $\mathrm{TXA}_{2}$ is produced in the vascular pole of the kidney in the vicinity of the changes in vascular resistance induced by the TGF response (9-11). In a preliminary account, Franco, Bell, and Navar (22) report no effect of either UK or a TX receptor antagonist (EP 092) on TGF responses when these drugs were added directly to the tubular perfusate. Moreover, in our study, SQ had no demonstrable effects on whole kidney excretion of fluid, $\mathrm{Na}^{+}, \mathrm{K}^{+}$, or $\mathrm{Cl}^{-}$, although there was a small 
increase in $\mathrm{U}_{\mathrm{Cl}} \mathrm{V}$ with $\mathrm{UK}$. These data suggest that the effects of these drugs were not primarily on the sensing site at the macula densa (tubular reabsorption) but on the effector site, i.e., that they modulated the sensitivity of the responses to signals from the macula densa cells. Our conclusions differ from those of Franco et al. (22) who found no effect of systemic administration of EP092 (a TX-receptor antagonist) in four rats at a dose of $1.2 \mathrm{mg} \cdot \mathrm{kg}^{-1} \cdot \mathrm{h}^{-1}$ on the TGF response. The reasons for this difference are not clear, but their preparation might not have the same TX dependency as ours. Alteratively, the dose of the antagonist used by Franco et al. (22) may have been inadequate.

Persson, Gushwa, and Blantz (7) observed that the combined administration of a cyclooxygenase inhibitor (meclofenamate) and an angiotensin-converting enzyme inhibitor (MK-421) abolished TGF-induced changes in $\mathbf{P}_{\mathrm{sf}}$, while only blunting changes in SNGFR. They proposed that the changes in SNGFR at constant glomerular capillary pressure reflected parallel alterations in pre- and postglomerular vascular resistances. We observed quite comparable degrees of inhibition of the overall TGF response assessed from measurements of SNGFR or $\mathrm{P}_{\mathrm{sf}}$ in rats treated with either a cyclooxygenase inhibitor, a TX synthetase inhibitor, or TX receptor antagonists. This is consistent with the effects of TX or stable mimetics in increasing vascular resistance, especially at preglomerular sites, when added to the perfusate of isolated kidneys and in constricting isolated glomeruli (23). These data indicate that $\mathrm{TXA}_{2}$ modulates TGF-induced changes in SNGFR, at least in part by regulating the glomerular pressure.

\section{Acknowledgments}

We are grateful to J. Mehta, M.D., for helpful advice in planning these studies, to P. Urquilla, M.D., of Pfizer Central Research, Groton, CT, for supplying UK-38,485, to A. W. Ford-Hutchinson, Ph.D., and G. Letts, Ph.D., of Merck-Frosst Canada, Inc., Point-Claire, Dorval, Quebec, Canada, for supplying L-641,953, and to Martin L. Ogletree, Ph.D., of the Squibb Institute for Medical Research, Princeton, NJ, for supplying SQ-29,548. We are grateful to Garrett Fitzgerald, M.D., of the Department of Clinical Pharmacology, Vanderbilt University Medical School, Nashville, TN, for the GCMS validation of the $\mathrm{TXB}_{2}$ assay. Harold Snellen provided expert technical assistance in the PG analyses.

This work was supported by grants from National Institutes of Health (ROI-AM36079 and 2ROIDK-HL36079).

\section{References}

1. Schnermann, J., D. W. Ploth, and M. Hermle. 1970. Activation of tubuloglomerular feedback by chloride transport. Pfluegers Arch. Eur. J. Physiol. 318:147-175.

2. Ichikawa, I. 1982. Direct analysis of the effector mechanism of the tubuloglomerular feedback system. Am. J. Physiol. 243:F447F455.

3. Ploth, D. W., and R. N. Roy. 1982. Renin-angiotensin influences on tubuloglomerular feedback activity in the rat. Kidney Int. 22(Suppl. 12):S114-S121.

4. Schnermann, J., G. Schubert, M. Hermle, R. Herbst, R. T. Stowe, S. Yarimizu, and P. C. Weber. The effect of inhibition of prostaglandin synthesis on tubuloglomerular feedback in the rat kidney. Pfluegers Arch. Eur. J. Physiol. 379:269-279.
5. Persson, A. E. G., U. Boberg, B. Hahme, R. Muller-Suur, B. J. Norben, and G. Selen. 1982. Interstitial pressure as a modulator of tubuloglomerular feedback control. Kidney Int. 22(Suppl. 12):S122S128.

6. Hahne, B., G. Selen, and A. E. G. Persson. 1984. Indomethacin inhibits renal functional adaptation to nephron loss. Renal Physiol. 7:13-21.

7. Persson, A. E. G., L. C. Gushwa, and R. C. Blantz. 1984. Feedback pressure-flow responses in normal and angiotensin-prostaglandin-blocked rats. Am. J. Physiol. 247:F925-F931.

8. Wilcox, C. S., S. Roddis, W. S. Peart, D. Gordon, and G. P. Lewis. 1985. Intrarenal prostaglandin release: effects of arachidonic acid and hyperchloremia. Kidney Int. 28:43-45.

9. Hassid, A., M. Konieczkowski, and M. J. Dunn. 1979. Prostaglandin synthesis in isolated rat kidney glomeruli. Proc. Natl. Acad. Sci. USA. 76:1155-1159.

10. Sraer, J., W. Siess, L. Moulonguet-Doleris, J. Oudinet, F. Dray, and $\mathbf{R}$. Ardaillou. In vitro prostaglandin synthesis by various rat renal preparations. Biochim. Biophys. Acta. 710:45-52.

11. Farman, N., P. Pradelles, and J. P. Bonvalet. 1987. PGE 2 ,

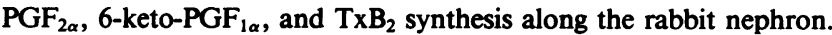
Am. J. Physiol. 252:F53-F59.

12. Klotman, P. E., S. R. Smith, B. D. Volpp, T. M. Coffman, and W. E. Yarger. 1986. Thromboxane synthetase inhibition improves function of hydronephrotic rat kidneys. Am. J. Physiol. 250:F282F287.

13. Remuzzi, G., L. Imberti, M. Rossini, C. Morelli, C. Carminati, G. M. Cattaneo, and T. Bertani. 1985. Increased glomerular thromboxane synthesis as a possible cause of proteinuria in experimental nephrosis. J. Clin. Invest. 75:94-101.

14. Udermann, H. D., E. K. Jackson, D. Puett, and R. J. Workman. 1984. Thromboxane synthetase inhibitor UK 38,485 lowers blood pressure in the adult spontaneously hypertensive rat. J. Cardiovasc. Pharmacol. 6:969-972.

15. Zipser, R. D., I. Dronborg, W. Rector, T. Reynolds, and G. Daskalpoulos. 1984. Therapeutic trial of thromboxane synthesis inhibition in the hepatorenal syndrome. Gastroenterology. 87:1228-1232.

16. Gordon, D., A. M. E. Nouri, and R. U. Thomas. 1981. Selective inhibition of thromboxane biosynthesis in human blood mononuclear cells and the effects on mitogen-stimulated lymphocyte proliferation. Br. J. Pharmacol. 74:469-475.

17. Ogletree, M. L., D. N. Harris, R. Greenberg, M. F. Haslanger, and M. Nakone. 1984. Pharmacological actions of SQ 29,548, a novel selective thromboxane antagonist. J. Pharmacol. Exp. Ther. 224:435441.

18. Hall, R. A., J. R. Rokach, P. Belanger, L. Bianchi, D. Ethier, A. W. Ford-Hutchinson, Y. Girard, P. Hamel, R. Hamel, A. Lord, and P. Yusko. 1987. L641-953, (R-8-fluoro-dibenzo[b,f]thiepin-3-carboxylic acid-5-oxide): a novel thromboxane-prostaglandin endoperoxide antagonist. Can. J. Physiol. Pharmacol. 65:509-514.

19. Wilcox, C. S. 1978. The effect of increasing the plasma magnesium concentration on renin release from the dog's kidney: interactions with calcium and sodium. J. Physiol. 284:203-217.

20. Humphrey, P. P. A., P. Lumley, and B. P. White. 1987. The agonist action of AH23848 at guinea-pig vascular and airway smooth muscle Tx-receptors in vivo. Br. J. Pharmacol. 90:820-826.

21. Wilcox, C. S., and W. J. Welch. 1987. Modulation of renin release by thromboxane in the anesthetized rat. Fed. Proc. 46:1066. (Abstr.)

22. Franco, M., P. D. Bell, L. G. Navar. 1987. Evaluation of prostaglandins as mediators of tubuloglomerular feedback. Kidney Int. 31:423. (Abstr.)

23. Loutzenhiser, R., M. Epstein, C. Horton, and P. Sonke. 1986. Reversal of renal and smooth muscle actions of the thromboxane mimetic U-44069 by diltiazem. Am. J. Physiol. 250:F619-F626. 